\title{
Efficacy and safety of prolonged-release versus immediate-release tacrolimus in de novo liver transplant recipients in South Korea: a randomized open-label phase 4 study (MAPLE)
}

\author{
Myoung Soo Kim ${ }^{1}$, Jae-Won Joh ${ }^{2}$, Dong-Sik $\mathrm{Kim}^{3}$, Seoung Hoon $\mathrm{Kim}^{4}$, Jin Sub Choi ${ }^{5}$, Jaegeun Lee ${ }^{1}$ \\ Jee Youn Lee ${ }^{6}$, Jong Man $\mathrm{Kim}^{2}$, Choon Hyuck David Kwon ${ }^{2}$, Gyu-Seong Choi ${ }^{2}$, Young Dong $\mathrm{Yu}^{7}$, \\ Yong-In Yoon ${ }^{8}$, Jae Hyun Han ${ }^{9}$, Yun Jeong Lee ${ }^{10}$, Hongsi Jiang ${ }^{11}$, Soon-II Kim ${ }^{1}$ \\ ${ }^{1}$ Department of Transplant Surgery, Severance Hospital, Yonsei University College of Medicine, Seoul, Korea; \\ ${ }^{2}$ Department of Surgery, Samsung Medical Center, Seoul, Korea; \\ ${ }^{3}$ Department of Surgery, Korea University College of Medicine, Seoul, Korea; \\ ${ }^{4}$ Department of Hepatobiliary Surgery, National Cancer Center, Seoul, Korea; \\ ${ }^{5}$ Department of Hepatobiliary-Pancreas Surgery, Severance Hospital, Yonsei University College of Medicine, Seoul, Korea; \\ ${ }^{6}$ Department of Surgery, Kangbuk Samsung Hospital, Seoul, Korea; \\ ${ }^{7}$ Department of Hepatobiliary Surgery, Korea University Anam Hospital, Seoul, Korea; \\ ${ }^{8}$ Department of Hepatobiliary Surgery, Asan Medical Center, Seoul, Korea; \\ ${ }^{9}$ Department of Surgery, St. Vincent's Hospital, The Catholic University of Korea, Seoul, Korea; \\ ${ }^{10}$ Astellas Pharma Inc., Seoul, Korea; \\ ${ }^{11}$ Astellas Pharma Inc., Singapore
}

Background: Prolonged-release tacrolimus is associated with better long-term graft and patient survival than the immediate-release formulation in liver transplant patients. However, no clinical data are available to assess the efficacy and safety of early conversion from twice-daily, immediate-release tacrolimus to once-daily, prolonged-release tacrolimus in de novoliver transplant recipients in Korea. Methods: A 24-week, randomized, open-label study was conducted in 36 liver transplant recipients. All patients received immediaterelease tacrolimus $\left(0.1^{-} 0.2 \mathrm{mg} / \mathrm{kg} /\right.$ day, divided into two doses) for 4 weeks after transplantation, at which time $50 \%$ of the patients were converted, at a ratio of $1 \mathrm{mg}$ to $1 \mathrm{mg}$, to prolonged-release tacrolimus (once-daily). The primary efficacy endpoint was the incidence of biopsy-confirmed acute rejection (BCAR) from weeks 4 to 24 after transplantation (per-protocol set). Medication adherence, adverse event profiles, laboratory tests, vital signs, and physical changes were also recorded.

Results: BCAR frequency at 24 weeks was similar between the two treatment groups; two cases (mean \pm standard deviation, $0.14 \pm 0.53$ cases) of BCAR were reported in one patient treated with prolonged-release tacrolimus ( $\mathrm{n}=14$ ), while no such cases were reported among patients treated with immediate-release tacrolimus $(n=12)$. The tacrolimus blood concentration at weeks 12 and 24, medication adherence, and adverse event profiles were also similar between the formulations, with no unusual laboratory test results, vital signs, or physical changes reported.

Conclusions: Early conversion to a simplified, once-daily, prolonged-release tacrolimus regimen may be an effective treatment option for liver transplant recipients in Korea. Larger-scale studies are warranted to confirm non-inferiority to immediate-release tacrolimus formulation in de novo liver transplant recipients.

Keywords: Immunosuppressive agents; Humans; Liver transplantation; Prolonged-release tacrolimus; Republic of Korea; Treatment outcome

Received September 27, 2018, Revised March 27, 2019, Accepted March 31, 2019

Correspondence to: Soon-II Kim

Department of Transplant Surgery, Severance Hospital, Yonsei University College of Medicine, 50-1 Yonsei-ro, Seodaemun-gu, Seoul 03772, Korea Tel: +82-2-2228-2118, Fax: +82-2-313-8239, E-mail: soonkim@yuhs.ac

This is an Open Access article distributed under the terms of the Creative Commons Attribution Non-Commercial License (http://creativecommons.org/ licenses/by-nc/4.0/) which permits unrestricted non-commercial use, distribution, and reproduction in any medium, provided the original work is properly cited. 


\section{INTRODUCTION}

Tacrolimus treatment has become the cornerstone of immunosuppressive regimens to prevent allograft rejection after liver transplantation [1]. While advances in immunosuppressive regimens have significantly improved patient and graft survival [2], it remains difficult to further optimize post-transplantation outcomes. Clinical use of tacrolimus is complicated by high intrapatient variability in whole-blood tacrolimus levels and medication nonadherence [3-5].

Various oral tacrolimus formulations are available after liver transplantation [6], including immediate-release capsules, which are taken twice daily, and newer, prolongedrelease formulations, which are taken once daily in the morning. Prolonged-release tacrolimus is associated with greater treatment adherence than immediate-release formulations. It also shows lower intrapatient variability and can improve long-term transplant outcomes [2,7-11], as reported in a large retrospective analysis conducted by the European Liver Transplant Registry, which compared the two formulations in primary liver transplant recipients from 21 European centers. In multivariate analyses, the once-daily formulation was associated with superior 3-year graft and patient survival compared with the twice-daily formulation [2].

Multiple studies have shown that stable liver transplant recipients can be converted from immediate-release to prolonged-release tacrolimus without impacting efficacy or safety [4,12-17], and that patients prefer once-daily dosing [17]. Most of these studies, including those conducted in Korea $[16,17]$, have involved conversion to prolonged- release tacrolimus 1 year after transplantation. However, no published, prospective, clinical data have assessed the efficacy and safety of early conversion to prolonged-release tacrolimus in de novo liver transplant recipients in Korea.

In the present study, we carried out the first direct comparison of the two oral tacrolimus formulations in Korean de novo liver transplant recipients who had converted from immediate-release to prolonged-release tacrolimus 4 weeks after transplantation.

\section{METHODS}

\section{Study Design and Patients}

This was a 24-week, randomized, open-label, phase 4 study conducted at four tertiary hospitals in South Korea from January 2013 to January 2017. The study was conducted in accordance with Korean Good Clinical Practice, the guidelines of the International Council for Harmonisation, and the Declaration of Helsinki (ClinicalTrials.gov: NCT 03423225). Written informed consent to participate in the study was obtained from all patients.

Adult men and women aged between 20 and 65 years who had terminal hepatic failure and were scheduled to receive a liver transplant were eligible to enter the study. The exclusion criteria were (1) previous organ transplant, (2) auxiliary transplant or use of a bioartificial liver, (3) allergy or resistance to macrolide antibiotics or tacrolimus, (4) immunosuppressive treatment or chemotherapy before transplant, unless the patient had been treated for a hepatic disorder for less than 1 month and treatment had been discontinued at the time of transplantation, and (5) malignancy within the past 5 years. Women of childbearing age

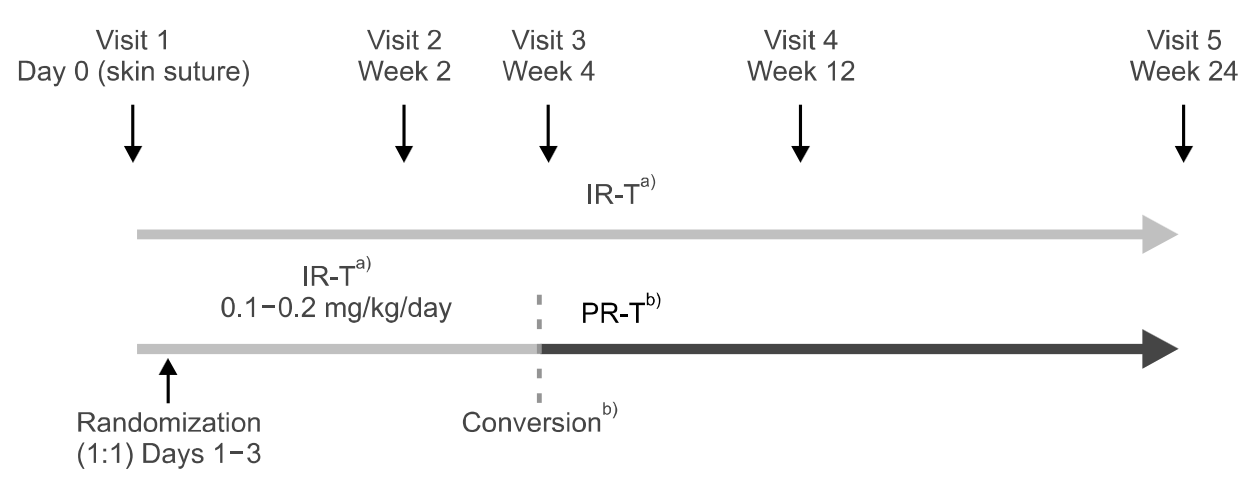

Fig. 1. Overview of study design. IR-T, immediate-release tacrolimus; PR-T, prolonged-release tacrolimus.

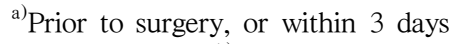
after surgery; ${ }^{\text {b) }}$ Conversion from IR-T on a 1:1 (mg:mg) total-dailydose basis. 
were required to provide a negative serum pregnancy test and to take double contraception.

\section{Study Treatment}

Eligible patients received immediate-release tacrolimus (Prograf; Astellas Pharma Europe Ltd., Chertsey, UK) from day 0 to week 4 . They were then equally randomized (1:1) to receive either prolonged-release tacrolimus (Advagraf; Astellas Pharma Europe, Leiden, the Netherlands) or immediate-release tacrolimus until week 24 (Fig. 1). A randomization schedule for each study center was completed by Linical Korea Ltd. (Seoul, Korea) and randomization codes were generated using a block randomization method stratified by investigational site.

Either before surgery or within 3 days of transplantation, all patients received immediate-release tacrolimus capsules at an initial dose of $0.1-0.2 \mathrm{mg} / \mathrm{kg} /$ day, divided into two doses. At the week 4 visit, the allocated patients were converted on a 1:1 dosage basis to prolonged-release tacrolimus capsules [18].

From day 0 to 30, individual tacrolimus doses were adjusted based on target tacrolimus whole-blood trough levels of $5-15 \mathrm{ng} / \mathrm{mL}$. After day 30, the target whole-blood trough levels were 3-12 ng/mL. Steroids, mycophenolate mofetil, azathioprine, and basiliximab were permitted as concomitant medications.

\section{Endpoints}

Efficacy and safety assessments were carried out at weeks 12 and 24. The primary efficacy endpoint was the incidence of biopsy-confirmed acute rejection (BCAR) from weeks 4 to 24 after transplantation. Secondary efficacy endpoints included the incidence of BCAR from weeks 4 to 12 , the severity and frequency of BCAR, patient and graft survival, and tacrolimus trough levels. Adverse events, adverse drug reactions, and abnormal clinical findings were assessed in all patients who received at least one dose of study drug. The severity of adverse events was classified as: (1) mild, does not interfere with normal activities; (2) moderate, significantly interferes with normal activities; or (3) severe, requires intensive treatment and may be life-threatening. Vital signs (weight, blood pressure, body temperature, and pulse), laboratory parameters, and physical changes were assessed at each study visit, and adherence with the study medication was assessed in terms of the number of returned capsules.

\section{Statistical Analysis}

Based on previous studies [19-21], the anticipated postsurgery acute rejection rate was approximately $15 \%$ up to week 4 and $50 \%$ up to week 24; the acute rejection rate from week 4 to 24 was therefore estimated at 35\% (50\%$15 \%)$. Assuming a $10 \%$ dropout rate, a total of 88 patients (44 per treatment arm) were required to yield a power of at least $80 \%$ to detect a significant difference $5 \%$ significance level) in confirmed week 4-24 acute rejection rates between the two groups.

The main analysis population to evaluate treatment efficacy was the per-protocol set (PPS), which comprised patients who had received at least one dose of study medication after randomization and who had completed the study without major protocol deviation. To assess the robustness of the primary analysis result, supportive analyses were carried out on the full-analysis set: the overall population who had received at least one dose of study medication. Safety analyses were carried out on the safety set (all patients who had received at least one dose of study medication) and were based on the actual treatment administered, irrespective of group assignment.

The primary objective of this study was to demonstrate that prolonged-release tacrolimus was not inferior to immediate-release tacrolimus in terms of the BCAR incidence from weeks 4 to 24 after transplantation. Noninferiority was assessed using a pre-specified margin of $30 \%$. That is, if the upper $95 \%$ confidence limit of the difference between the immediate-release and prolongedrelease treatment groups was $<30 \%$, noninferiority was confirmed. Differences in incidence were calculated using Fisher's exact test. Between-group differences in tacrolimus trough levels were tested using the either the two-sample t-test or Wilcoxon rank-sum test. The statistical significance of between-group differences in adverse events and adverse drug reactions was tested using either the chi-square test or Fisher's exact test. Statistical evaluations were performed using the SAS statistical software package ver. 9.3 (SAS Institute Inc., Cary, NC, USA). 
The overall adherence rate was calculated as a percentage by dividing the number of capsules administered by the planned number of capsules per day multiplied by the overall duration of administration.

\section{RESULTS}

\section{Study Population}

We had difficulties in recruiting sufficient patient numbers, so we closed study enrollment early. Ultimately, $36 \mathrm{pa}-$ tients were randomized (prolonged-release tacrolimus: $\mathrm{n}=19$, immediate-release tacrolimus: $\mathrm{n}=17$ ), 26 of whom completed the study and were included in the PPS. Two patients in each treatment group were not treated, and three in each had protocol deviations (Fig. 2). The reasons for withdrawal were as follows: violation of inclusion/exclusion criteria (prolonged-release tacrolimus group: $n=2$ ), graft loss (immediate-release tacrolimus group: $\mathrm{n}=1$ ), and others (immediate-release tacrolimus group: $\mathrm{n}=1$, prolongedrelease tacrolimus group: $n=2$ ). Because the sample size was smaller than planned, the study had insufficient power to make the planned between-group comparisons.

A total of 12 major protocol deviations (six in the prolonged-release and six in the immediate-release tacrolimus groups) occurred in 10 patients, namely concomitant prohibited medication ( $\mathrm{n}=2$ ), less than $80 \%$ adherence $(n=2)$, withdrawal $(n=6$; violation of inclusion/exclusion criteria $[n=2]$, death $[n=2]$, graft loss $[n=1]$, incompatible blood groups $[n=1]$, violation of administration method

Table 1. Baseline patient demographics and characteristics

\begin{tabular}{|c|c|c|c|}
\hline Characteristics & $\begin{array}{l}\text { Prolonged-release } \\
\text { tacrolimus }(n=17)\end{array}$ & $\begin{array}{l}\text { Immediate-release } \\
\text { tacrolimus }(n=15)\end{array}$ & P-value \\
\hline Male sex & $11(64.7)$ & $11(73.3)$ & $0.712^{\mathrm{a})}$ \\
\hline Age $(y r)$ & & & $0.449^{b)}$ \\
\hline Mean \pm SD & $55.0 \pm 8.3$ & $52.7 \pm 8.9$ & \\
\hline Median (range) & $56.0(42.0-65.0)$ & $56.0(33.0-65.0)$ & \\
\hline Height $(\mathrm{cm})$ & & & $0.174^{\mathrm{a})}$ \\
\hline Mean $\pm \mathrm{SD}$ & $162.5 \pm 9.06$ & $167.0 \pm 9.3$ & \\
\hline Median (range) & $162.0(148.0-180.0)$ & $167.0(151.0-181.0)$ & \\
\hline \multicolumn{4}{|c|}{ Blood (RH) } \\
\hline $\mathrm{RH}+$ & $17(100.0)$ & $15(100.0)$ & \\
\hline $\mathrm{RH}^{-}$ & 0 & 0 & \\
\hline Blood type $(\mathrm{ABO})$ & & & $0.102^{\mathrm{b})}$ \\
\hline A & $4(23.5)$ & $4(26.7)$ & \\
\hline $\mathrm{B}$ & $7(41.2)$ & $3(20.0)$ & \\
\hline $\mathrm{AB}$ & $1(5.9)$ & $6(40.0)$ & \\
\hline $\mathrm{O}$ & $5(29.4)$ & $2(13.3)$ & \\
\hline \multicolumn{4}{|l|}{ Infection status } \\
\hline HIV, positive & 0 & 0 & \\
\hline $\mathrm{HBV}$, positive & $9(52.9)$ & $9(60.0)$ & $0.688^{\mathrm{c})}$ \\
\hline $\mathrm{HCV}$, positive & $3(17.7)$ & $1(6.7)$ & $0.603^{\mathrm{b})}$ \\
\hline CMV, positive & $14(82.4)$ & $14(93.3)$ & $0.603^{\mathrm{b})}$ \\
\hline EBV, positive & $14(82.4)$ & $9(64.3)$ & $0.413^{\mathrm{b})}$ \\
\hline
\end{tabular}

Values are presented as number (\%) unless otherwise indicated. $\mathrm{SD}$, standard deviation; RH, Rhesus type; HIV, human immunodeficiency virus antigen/antibody; $\mathrm{HBV}$, hepatitis $\mathrm{B}$ virus; $\mathrm{HCV}$, hepatitis $\mathrm{C}$ virus; CMV, cytomegalovirus; EBV, Epstein-Barr virus.

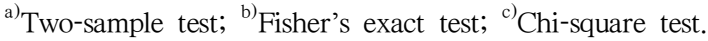

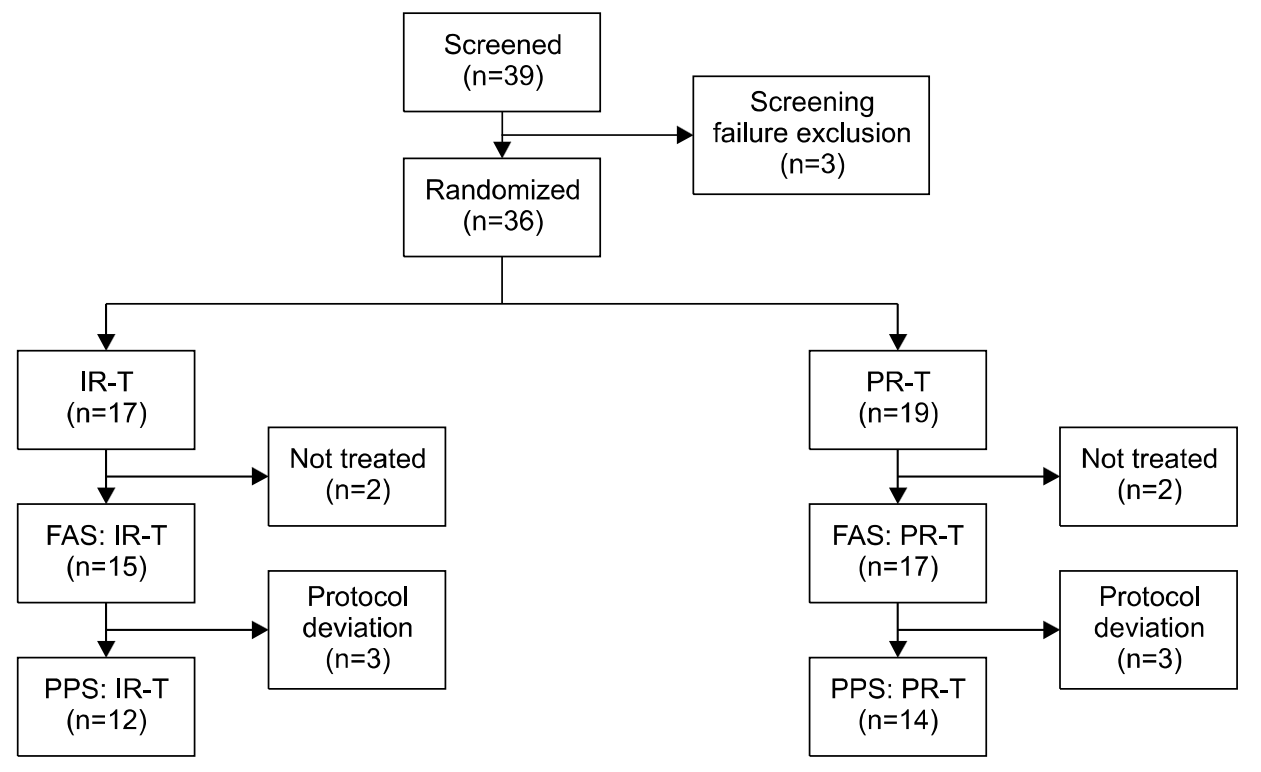

Fig. 2. Patient flow throughout the study. Overall, 26 patients completed the study (PPS). The reasons for withdrawal were (1) violation of inclusion/exclusion criteria (prolongedrelease tacrolimus group: $\mathrm{n}=2),(2)$ graft loss (immediate-release tacrolimus group: $n=1$ ), and (3) others (immediate-release tacrolimus group: $\mathrm{n}=1$, prolonged-release tacrolimus group: $n=2$ ). IR- $T$, immediate-release tacrolimus; FAS, full-analysis set (patients who received at least one dose of investigational product); PPS, perprotocol set (patients who received at least one dose of study medication and completed the study without major protocol deviation); PR-T, prolonged-release tacrolimus. 
$(n=1)$, and violation of inclusion/exclusion criteria $(n=1)$.

At baseline, there were no major differences between the treatment groups in any demographic characteristics, including blood group and virus infection status (Table 1). After taking the study medication, a similar proportion of patients received concomitant immunosuppressant medication (17 patients in the prolonged-release tacrolimus group and 14 in the immediate-release group).

\section{Tacrolimus Trough Level}

At baseline, i.e., at the time of switching (week 4), tacrolimus trough levels (mean \pm standard deviation [SD]) were higher in the prolonged-release tacrolimus group than in the immediate-release tacrolimus group (8.8 \pm 2.2 and $6.9 \pm 1.4$, respectively). The trough levels at weeks 12 and 24 were similar (Table 2). Changes in trough levels from baseline to weeks 12 and 24 were also similar between the two treatment groups (Table 2).

\section{Biopsy-Confirmed Acute Rejection}

One patient in the prolonged-release tacrolimus group experienced two cases of moderate rejection; the frequency (mean \pm SD; PPS) was $0.07 \pm 0.27$ (one case in one patient) at week 12 and $0.14 \pm 0.53$ (two cases in one patient) at week 24 . This patient's acute rejection was treated using

Table 3. Incidence of biopsy-confirmed acute rejection at week 24

\begin{tabular}{lcccc}
\hline Variable & $\begin{array}{c}\text { Prolonged- } \\
\text { release } \\
\text { tacrolimus }\end{array}$ & $\begin{array}{c}\text { Immediate- } \\
\text { release } \\
\text { tacrolimus }\end{array}$ & $\begin{array}{c}\text { Difference } \\
(95 \% \mathrm{CI})\end{array}$ & P-value \\
\hline PPS & & & & $1.000^{\text {b) }}$ \\
Number & 14 & 12 & & \\
BCAR & $1(7.1)$ & 0 & $7.1(-6.4$ to 20.6$)$ & $1.000^{\text {b) }}$ \\
FAS & 17 & 15 & & \\
Number & $17(5.8)$ & 0 & $5.9(-5.3$ to 17.1$)$ & \\
BCAR & $1(5)$ & & &
\end{tabular}

Values are presented as number $(\%)$ unless otherwise indicated. CI, confidence interval; PPS, per-protocol set; BCAR, biopsy confirmed acute rejection; FAS, full-analysis set.

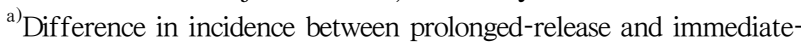
release tacrolimus and $95 \%$ two-sided confidence interval for the difference; ${ }^{\text {b) }}$ Fisher's exact test.

Table 2. Whole-blood tacrolimus concentration and change from baseline tacrolimus concentration at week 12 and week 24 (PPS)

\begin{tabular}{|c|c|c|c|}
\hline Variable & $\begin{array}{l}\text { Prolonged-release tacrolimus } \\
\qquad(\mathrm{n}=14)\end{array}$ & $\begin{array}{l}\text { Immediate-release tacrolimus } \\
\qquad(\mathrm{n}=12)\end{array}$ & P-value \\
\hline Baseline (week 4) & & & $0.018^{\mathrm{a})}$ \\
\hline Mean \pm SD & $8.8 \pm 2.2$ & $6.9 \pm 1.4$ & \\
\hline Median (range) & $8.8(3.9$ to 12.9$)$ & $6.9(4.7$ to 9.6$)$ & \\
\hline Week 12 & & & $0.903^{\mathrm{a})}$ \\
\hline Mean \pm SD & $6.7 \pm 3.2$ & $6.6 \pm 2.3$ & \\
\hline Median (range) & $6.6(2.9$ to 14.9$)$ & $6.0(3.3$ to 11.0$)$ & \\
\hline Week 24 & & & $0.837^{\mathrm{b})}$ \\
\hline Mean \pm SD & $7.1 \pm 2.8$ & $7.9 \pm 4.0$ & \\
\hline Median (range) & $7.3(2.7$ to 12.8$)$ & $6.2(4.2$ to 16.9$)$ & \\
\hline Change from baseline at week 12 & & & $0.212^{a)}$ \\
\hline Mean \pm SD & $-2.1 \pm 4.1$ & $-0.3 \pm 2.4$ & \\
\hline Median (range) & $-2.8(-9.4$ to 6.1$)$ & $-0.6(-3.4$ to 5.1$)$ & \\
\hline $\begin{array}{l}\text { P-value for within-group difference in observed } \\
\text { value between baseline and week } 12\end{array}$ & $0.081^{\mathrm{c})}$ & $0.632^{\mathrm{c})}$ & \\
\hline Change from baseline at week 24 & & & $0.110^{\mathrm{a})}$ \\
\hline Mean \pm SD & $-1.7 \pm 3.4$ & $0.93 \pm 4.6$ & \\
\hline Median (range) & $-2.2(-6.1$ to 5.5$)$ & $-1.1(-4.1$ to 11.0$)$ & \\
\hline $\begin{array}{l}\text { P-value for within-group difference in observed } \\
\text { value at baseline and week } 24\end{array}$ & $0.088^{\mathrm{c})}$ & $0.501^{\mathrm{c})}$ & \\
\hline
\end{tabular}

Values are in $\mathrm{ng} / \mathrm{mL}$.

PPS, per protocol set; SD, standard deviation.

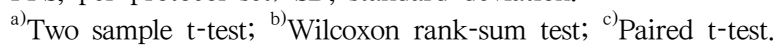


corticosteroid pulse therapy; however, the patient's condition did not improve, and a liver biopsy was performed. From the biopsy results, the investigator judged that the patient's elevated aspartate transaminase (AST)/alanine transaminase (ALT) ratio and T-bilirubin levels were due to biliary stricture and inserted a percutaneous, transhepatic biliary drainage tube into the patient. The patient's AST/ALT and T-bilirubin levels subsequently decreased, and they were discharged. The cause of the acute rejection was reported as biliary stricture.

No patients in the immediate-release tacrolimus group experienced BCAR (Table 3). The upper 95\% confidence limit of the between-group difference was below the predefined threshold of 30\% (20.6\%). However, the study had insufficient power to claim non-inferiority, which was the primary objective. Identical results were observed for the BCAR rate at week 12, and both findings were supported in the results from the full-analysis set.

\section{Patient/Graft Survival}

One patient in the prolonged-release tacrolimus group died due to sepsis (unrelated to the study drug). The patient survival rates at week 24 were $94.1 \%$ (95\% confidence interval, $65.0 \%$ to $99.2 \%$ ) and $100.0 \%$ in the prolongedrelease and immediate-release tacrolimus groups, respectively. No patients in either group had retransplantation or death as a result of graft loss.

\section{Medication Adherence}

Medication adherence was high and similar between groups: $94.8 \%$ in the prolonged-release and $94.4 \%$ in the immediate-release tacrolimus group (Table 4).

\section{Safety}

Of the 32 randomized patients in the safety set, $26(81.3 \%)$ developed 102 adverse events; 65 of these events occurred in 15 patients (88.2\%) in the prolonged-release tacrolimus group, and 37 occurred in 11 patients $(73.3 \%)$ in the immediate-release tacrolimus group. Adverse events with an incidence $\geq 10 \%$ were generally similar in each treatment group (Table 5). The majority of adverse events (94.1\%) were mild or moderate in severity. One patient in the prolonged-release tacrolimus group, experienced a treatment-related adverse event (sepsis) and subsequently died, but the adverse event was considered unrelated to study drug. Five patients (15.6\%; four in the prolongedrelease group and one in the immediate-release tacrolimus group) had 10 episodes of elevated liver function tests and/or bilirubin levels. Of these patients, all were taking concomitant methylprednisolone, four were taking mycophenolate, and two had also been prescribed deflazacort (glucocorticoid). After elevated liver function test/bilirubin had been identified, tacrolimus dosage was increased in one patient in the prolonged-release group, decreased in one patient in the prolonged-release group, and maintained in one patient in the prolonged-release group. The dosage was unavailable in two of the patients. Adverse drug reactions were experienced by five patients (29.4\%) in the prolonged-release group and two patients (13.3\%) in the immediate-release group. No unusual laboratory

Table 4. Medication adherence in the full-analysis set

\begin{tabular}{|c|c|c|c|}
\hline Variable & Prolonged-release tacrolimus $(n=17)$ & Immediate-release tacrolimus $(\mathrm{n}=15)$ & P-value \\
\hline Medication adherence $(\%)$ & & & $0.240^{\mathrm{a})}$ \\
\hline Mean \pm SD & $94.8 \pm 4.8$ & $94.4 \pm 7.5$ & \\
\hline Median (range) & $99.4(41.3-110.8)$ & $95.8(76.6-104.0)$ & \\
\hline Medication adherence category & & & $1.000^{\mathrm{b})}$ \\
\hline$<80 \%$ & $1(5.9)$ & $1(6.7)$ & \\
\hline$\geq 80 \%$ to $<90 \%$ & $2(11.8)$ & $2(13.3)$ & \\
\hline$\geq 90 \%$ & $14(82.4)$ & $12(80.0)$ & \\
\hline
\end{tabular}

Values are presented as number (\%) unless otherwise indicated.

$\mathrm{SD}$, standard deviation.

${ }^{a}$ Wilcoxon rank-sum test; ${ }^{\text {b) }}$ Fisher's exact test. 
Table 5. Frequently occurring adverse events with an incidence $\geq 10 \%$ in each treatment group (SAF)

\begin{tabular}{|c|c|c|c|}
\hline $\begin{array}{l}\text { Adverse } \\
\text { event }\end{array}$ & $\begin{array}{l}\text { Prolonged-release } \\
\text { tacrolimus }(n=17)\end{array}$ & $\begin{array}{l}\text { Immediate-release } \\
\text { tacrolimus }(\mathrm{n}=15)\end{array}$ & $\begin{array}{c}\text { Total } \\
(n=32)\end{array}$ \\
\hline Abdominal pain & $2(11.8) / 2$ & $2(13.3) / 2$ & $4(12.5) / 4$ \\
\hline Constipation & 0 & $2(13.3) / 2$ & $2(6.3) / 2$ \\
\hline Diarrhea & $1(5.9) / 1$ & $2(13.3) / 2$ & $3(9.4) / 3$ \\
\hline Pyrexia & $2(11.8) / 4$ & $1(6.7) / 3$ & $3(9.4) / 7$ \\
\hline Bile duct stenosis & $2(11.8) / 2$ & 0 & $2(6.3) / 2$ \\
\hline CMV infection & $3(17.7) / 3$ & 0 & $3(9.4) / 3$ \\
\hline $\begin{array}{l}\text { Upper } \\
\text { respiratory } \\
\text { tract infection }\end{array}$ & $1(5.9) / 1$ & $2(1$ & $3(9.4) / 3$ \\
\hline $\begin{array}{l}\text { Blood bilirubin } \\
\text { increased }\end{array}$ & $2(11.8) / 2$ & 0 & $2(6.3) / 2$ \\
\hline $\begin{array}{l}\text { Liver function } \\
\text { test increased }\end{array}$ & $3(17.7) / 7$ & $1(6.7) / 1$ & $4(12.5) / 8$ \\
\hline $\begin{array}{l}\text { Electrolyte } \\
\text { imbalance }\end{array}$ & $2(11.8) / 2$ & 0 & $2(6.3) / 2$ \\
\hline Myalgia & $2(11.8) / 2$ & $1(6.7) / 1$ & $3(9.4) / 3$ \\
\hline Headache & $2(11.8) / 2$ & $2(13.3) / 2$ & $4(12.5) / 4$ \\
\hline Tremor & 0 & $2(13.3) / 2$ & $2(6.3) / 2$ \\
\hline Hypertension & $2(11.8) / 2$ & 0 & $2(6.3) / 2$ \\
\hline
\end{tabular}

Values are presented as number $(\%) /$ number of events. SAF, safety set; CMV, cytomegalovirus.

test results, vital signs, or physical changes were reported.

\section{DISCUSSION}

Evidence suggests that treatment with prolonged-release tacrolimus may improve long-term graft and patient survival compared with the immediate-release formulation in primary liver transplant recipients [2]. Early conversion to prolonged-release tacrolimus may help maximize these benefits. To our knowledge, this was the first prospective trial to compare early conversion to prolonged-release tacrolimus with continued immediate-release tacrolimus in de novo, South Korean liver transplant recipients. The results showed that once-daily, prolonged-release tacrolimus was effective when administered from 4 weeks after transplantation, and that it was similar to immediaterelease tacrolimus with respect to BCAR rates during the 24-week study period. No major differences in safety outcomes occurred between the prolonged-release and immediate-release tacrolimus formulations, and no new safety signals were observed in South Korean liver trans- plant recipients.

Because we had difficulty recruiting sufficient patients, we closed enrollment after only 36 patients had entered the study. Several issues may have contributed to this insufficient enrollment, including an outbreak of Middle East Respiratory Syndrome (MERS) that occurred during the trial, the strict inclusion/exclusion criteria, and the late addition of investigational sites. Due to the small sample size, our study had insufficient power to make comparisons between the treatment arms. Thus, our results are exploratory only, and require confirmation in a larger-scale trial. However, they are consistent with a previous study in a large $(n=475)$, predominantly Caucasian population of de novo liver transplant recipients [6], in which prolonged-release tacrolimus started immediately after liver transplantation was not inferior to immediate-release tacrolimus with respect to rejection rates over 24 weeks. An open-label extension of the study then demonstrated similar efficacy and safety profiles for prolonged-release and immediate-release tacrolimus over 12 months of treatment [6].

In the present study, no patients required re-transplantation or died due to graft loss. Only one patient died of a non-drug related adverse event (sepsis). The patient survival rate at 24 weeks was similar between the treatment groups, and in the prolonged-release tacrolimus group, the rate $(94.1 \%)$ was consistent with the 6-month rates reported in a recently published trial that assessed three different prolonged-release tacrolimus regimens (89.1\%90.4\%) [22], as well as with other previous studies in $d e$ novo liver transplant recipients [6,23-25].

Whole-blood tacrolimus concentrations decreased after conversion to prolonged-release tacrolimus but remained within the target range and were stable between 12 and 24 weeks. This pattern of reduced tacrolimus trough levels after conversion to the prolonged-release formulation was consistent with other conversion trials in stable patients who had undergone liver transplant [12-16], and it may indicate that the prolonged-release formulation is absorbed at more distal regions of the gastrointestinal tract, where conditions for drug absorption are generally less favorable. Although similar BCAR rates and target trough levels were seen in both groups, clinicians must monitor 
tacrolimus concentrations closely at first to identify patients requiring dose adjustment after conversion to prolonged-release tacrolimus. In this regard, although patients randomized to be converted to prolonged-release tacrolimus showed significantly higher tacrolimus trough levels at week 4 in the present study $(8.8 \pm 2.2$ vs. $6.9 \pm 1.4 \mathrm{ng} / \mathrm{mL})$, the levels were well within the target range $(5-15 \mathrm{ng} / \mathrm{mL})$. Since the two patient groups had similar baseline characteristics and had been treated with exactly the same immediate-release tacrolimus regimen up to week 4 , this difference in trough levels was most likely a natural variation resulting from the small population size. We doubt this difference had any clinical significance or would have affected outcomes, especially as no significant difference in tacrolimus concentrations was seen between the groups at weeks 12 and 24 .

Previous studies have shown that patients prefer prolonged-release tacrolimus and that they adhere better to such regimens $[4,15,17,26]$. However, the present study showed no difference in adherence between the groups (prolonged-release, 94.8\%; immediate-release, 94.4\%), perhaps because the patient population was small and the study was only carried out over 24 weeks.

Conversion to prolonged-release tacrolimus was welltolerated, with a low incidence of treatment-related adverse events. Those adverse events that did occur were similar to those already associated with the immediaterelease formulation, as previously reported $[4,6,18]$.

Several studies have suggested that prolonged-release tacrolimus can be administered immediately after liver transplantation, provided that the tacrolimus trough level is strictly monitored and adjusted [6,27]. However, little practical information is available about initiating prolonged-release tacrolimus, and experts are cautious about using prolonged-release tacrolimus immediately after surgery when gastric motility changes might disturb its absorption [28]. We decided to initiate prolonged-release tacrolimus 4 weeks after transplantation based on changes to tacrolimus pharmacokinetics that occur in the early posttransplantation period [29]; furthermore, transplant physicians are already accustomed to using twice-daily tacrolimus and maintaining tacrolimus dose from 4 weeks after transplantation.
The present study had a number of limitations that should be addressed in a confirmatory trial. For example, the open-label design of the trial may have introduced bias, and the 24-week duration would not reveal differences in adverse event profiles emerging over the longer term. In addition, the study had insufficient power to confirm that prolonged-release tacrolimus is not inferior to immediate-release tacrolimus. Additionally, the 30\% noninferiority margin may have been too large, as it was double the non-inferiority margin used in a previous largescale study that compared the two formulations with respect to BCAR [6].

Despite these limitations, the present study does add to the limited available data comparing tacrolimus formulations in de novo liver transplant recipients. Furthermore, it was conducted among Asian patients, who have been under-represented in the tacrolimus studies conducted to date.

The present study, carried out in de novo liver transplant recipients, suggested that early posttransplant conversion from twice-daily tacrolimus to a simplified oncedaily dosing regimen with prolonged-release tacrolimus is an effective treatment option for liver transplant recipients in South Korea. These findings warrant confirmation in larger-scale studies.

\section{CONFLICT OF INTEREST}

This study was funded by Astellas Pharma Inc. and YJL and $\mathrm{HJ}$ are employees of Astellas Pharma Inc. No other potential conflict of interest relevant to this article was reported.

\section{ACKNOWLEDGMENTS}

This study was funded by Astellas Pharma Inc. All authors report non-financial support from Astellas Pharma Inc. during the conduct of the study. YJL and $\mathrm{HJ}$ are employees of Astellas Pharma Inc.

The authors wish to thank Lisa O'Rourke, PhD, and Amy MacLucas, $\mathrm{PhD}$, from Cello Health MedErgy, who assisted in drafting the initial version of the manuscript and provided support at all stages of the publication process. Editorial support was funded by Astellas Pharma Inc. 


\section{ORCID}

Myoung Soo Kim https://orcid.org/0000-0002-8975-8381

Jae-Won Joh https://orcid.org/0000-0003-1732-6210

Dong-Sik Kim https://orcid.org/0000-0002-0608-1580

Seoung Hoon Kim https://orcid.org/0000-0001-7921-1801

Jin Sub Choi https://orcid.org/0000-0002-6467-6494

Jaegeun Lee https://orcid.org/0000-0002-6722-0257

Jong Man Kim https://orcid.org/0000-0002-1903-8354

Choon Hyuck David Kwon

https://orcid.org/0000-0002-1082-3321

Young Dong Yu https://orcid.org/0000-0003-3452-338X

Yun Jeong Lee https://orcid.org/0000-0001-8940-5773

Hongsi Jiang https://orcid.org/0000-0001-6075-1015

Soon-Il Kim https://orcid.org/0000-0002-0783-7538

\section{REFERENCES}

1. Kim WR, Lake JR, Smith JM, Schladt DP, Skeans MA, Harper AM, et al. OPTN/SRTR 2016 annual data report: liver. Am J Transplant 2018;18 Suppl 1:172-253.

2. Adam R, Karam V, Delvart V, Trunečka P, Samuel D, Bechstein WO, et al. Improved survival in liver transplant recipients receiving prolonged-release tacrolimus in the European Liver Transplant Registry. Am J Transplant 2015;15:1267-82.

3. Christina S, Annunziato RA, Schiano TD, Anand R, Vaidya $\mathrm{S}$, Chuang $\mathrm{K}$, et al. Medication level variability index predicts rejection, possibly due to nonadherence, in adult liver transplant recipients. Liver Transpl 2014;20:1168-77.

4. Beckebaum S, Iacob S, Sweid D, Sotiropoulos GC, Saner F, Kaiser G, et al. Efficacy, safety, and immunosuppressant adherence in stable liver transplant patients converted from a twice-daily tacrolimus-based regimen to once-daily tacrolimus extended-release formulation. Transpl Int 2011; 24:666-75.

5. Rodrigue JR, Nelson DR, Hanto DW, Reed AI, Curry MP. Patient-reported immunosuppression nonadherence 6 to 24 months after liver transplant: association with pretransplant psychosocial factors and perceptions of health status change. Prog Transplant 2013;23:319-28.

6. Trunečka P, Boillot $\mathrm{O}$, Seehofer D, Pinna AD, Fischer L, Ericzon $\mathrm{BG}$, et al. Once-daily prolonged-release tacrolimus (ADVAGRAF) versus twice-daily tacrolimus (PROGRAF) in liver transplantation. Am J Transplant 2010;10:2313-23.

7. Considine A, Tredger JM, Heneghan M, Agarwal K, Samyn
M, Heaton ND, et al. Performance of modified-release tacrolimus after conversion in liver transplant patients indicates potentially favorable outcomes in selected cohorts. Liver Transpl 2015;21:29-37.

8. Stifft F, Stolk LM, Undre N, van Hooff JP, Christiaans MH. Lower variability in 24-hour exposure during once-daily compared to twice-daily tacrolimus formulation in kidney transplantation. Transplantation 2014;97:775-80.

9. Wu MJ, Chang $\mathrm{CH}$, Cheng $\mathrm{CY}$, Shu $\mathrm{KH}$, Chen $\mathrm{CH}$, Cheng $\mathrm{CH}$, et al. Reduced variability of tacrolimus trough level in once-daily tacrolimus-based Taiwanese kidney transplant recipients with high-expressive genotype of cytochrome P450 3A5. Transplant Proc 2014;46:403-5.

10. Kuypers DR, Peeters PC, Sennesael JJ, Kianda MN, Vrijens B, Kristanto P, et al. Improved adherence to tacrolimus once-daily formulation in renal recipients: a randomized controlled trial using electronic monitoring. Transplantation 2013;95:333-40.

11. Eberlin M, Otto G, Krämer I. Increased medication compliance of liver transplant patients switched from a twicedaily to a once-daily tacrolimus-based immunosuppressive regimen. Transplant Proc 2013;45:2314-20.

12. Dopazo C, Rodriguez R, Llado L, Calatayud D, Castells L, Ramos E, et al. Successful conversion from twice-daily to once-daily tacrolimus in liver transplantation: observational multicenter study. Clin Transplant 2012;26:E32-7.

13. Dumortier J, Guillaud O, Boillot O. Conversion from twice daily tacrolimus to once daily tacrolimus in long-term stable liver transplant recipients: a single-center experience with 394 patients. Liver Transpl 2013;19:529-33.

14. Sańko-Resmer J, Boillot O, Wolf P, Thorburn D. Renal function, efficacy and safety postconversion from twice- to once-daily tacrolimus in stable liver recipients: an openlabel multicenter study. Transpl Int 2012;25:283-93.

15. Valente G, Rinaldi L, Sgambato M, Piai G. Conversion from twice-daily to once-daily tacrolimus in stable liver transplant patients: effectiveness in a real-world setting. Transplant Proc 2013;45:1273-5.

16. Kim JM, Kwon CH, Joh JW, Sinn DH, Lee S, Choi GS, et al. Conversion of once-daily extended-release tacrolimus is safe in stable liver transplant recipients: a randomized prospective study. Liver Transpl 2016;22:209-16.

17. Kim SH, Lee SD, Kim YK, Park SJ. Conversion of twice-daily to once-daily tacrolimus is safe in stable adult living donor liver transplant recipients. Hepatobiliary Pancreat Dis Int 2015;14:374-9.

18. Astellas Pharma Europe. Advagraf $0.5 \mathrm{mg}, 1 \mathrm{mg}, 3 \mathrm{mg}$ and $5 \mathrm{mg}$ prolonged-release hard capsules summary of product characteristics. Leiden, NL: Astellas Pharma; 2015. 
19. U.S. Multicenter FK506 Liver Study Group. A comparison of tacrolimus (FK 506) and cyclosporine for immunosuppression in liver transplantation. N Engl J Med 1994; 331:1110-5

20. Margarit C, Bilbao I, Castells L, Lopez I, Pou L, Allende E, et al. A prospective randomized trial comparing tacrolimus and steroids with tacrolimus monotherapy in liver transplantation: the impact on recurrence of hepatitis $\mathrm{C}$. Transpl Int 2005;18:1336-45.

21. Jain AB, Kashyap R, Rakela J, Starzl TE, Fung JJ. Primary adult liver transplantation under tacrolimus: more than 90 months actual follow-up survival and adverse events. Liver Transpl Surg 1999;5:144-50.

22. Trunečka P, Klempnauer J, Bechstein WO, Pirenne J, Friman $\mathrm{S}$, Zhao A, et al. Renal function in de novo liver transplant recipients receiving different prolonged-release tacrolimus regimens: the DIAMOND Study. Am J Transplant 2015;15: 1843-54.

23. Uemoto S, Abe R, Horike H, So M. Safety and efficacy of once-daily modified-release tacrolimus in liver transplant recipients: a multicenter postmarketing surveillance in Japan. Transplant Proc 2014;46:749-53.

24. Gastaca M, Valdivieso A, Bustamante J, Fernández JR, Ruiz $\mathrm{P}$, Ventoso A, et al. Favorable longterm outcomes of liver transplant recipients treated de novo with once-daily tacrolimus: results of a single-center cohort. Liver Transpl 2016; 22:1391-400.

25. van Hooff JP, Alloway RR, Trunečka P, Mourad M. Four-year experience with tacrolimus once-daily prolonged release in patients from phase II conversion and de novo kidney, liver, and heart studies. Clin Transplant 2011;25:E1-12.

26. Guirado L, Cantarell C, Franco A, Huertas EG, Fructuoso AS, Fernández A, et al. Efficacy and safety of conversion from twice-daily to once-daily tacrolimus in a large cohort of stable kidney transplant recipients. Am J Transplant 2011;11:1965-71.

27. Okumura Y, Noda T, Eguchi H, Iwagami Y, Yamada D, Asaoka T, et al. Short- and long-term outcomes of de novo liver transplant patients treated with once-daily prolonged-release tacrolimus. Transplant Direct 2017;3:e207.

28. Coilly A, Calmus Y, Chermak F, Dumortier J, Duvoux C, Guillaud $\mathrm{O}$, et al. Once-daily prolonged release tacrolimus in liver transplantation: experts' literature review and recommendations. Liver Transpl 2015;21:1312-21.

29. Han N, Ha S, Yun HY, Kim MG, Min SI, Ha J, et al. Population pharmacokinetic-pharmacogenetic model of tacrolimus in the early period after kidney transplantation. Basic Clin Pharmacol Toxicol 2014;114:400-6. 